BATISTA, T. B.; CARDOSO, E. D.; BINOTTI, F. F. S.; SÁ, M. E.; HAGA, K. I. Nutrientes e giberelina no condicionamento fisiológico sob a qualidade de sementes de braquiária. Revista de Agricultura Neotropical, CassilândiaMS, v. 2, n. 1, p. 10-16, jan./mar. 2015.

\title{
NUTRIENTES E GIBERELINA NO CONDICIONAMENTO FISIOLÓGICO SOB A QUALIDADE DE SEMENTES DE BRAQUIÁRIA
}

\author{
THIAGO BARBOSA BATISTA ${ }^{1}$, ELIANA DUARTE CARDOSO ${ }^{1}$, FLÁVIO \\ FERREIRA DA SILVA BINOTTI ${ }^{1}$, MARCO EUSTÁQUIO DE SÁ ${ }^{2}$, KUNIKO \\ IWAMOTO HAGA ${ }^{2}$
}

\footnotetext{
${ }^{1}$ Universidade Estadual de Mato Grosso do Sul, Unidade de Cassilândia, Cassilândia/MS, Brasil, batistatb@hotmail.com, elianaduarte@uems.br, binotti@uems.br, ${ }^{2}$ Universidade Estadual Paulista Júlio de Mesquita Filho, Ilha Solteira/SP, Brasil, marcosa@agr.feis.unesp.br, kuniko@bio.feis.unesp.br
}

RESUMO: Condicionamento fisiológico por agentes químicos pode incrementar a produção e melhorar a qualidade fisiológica das sementes. Objetivou-se avaliar a influência de ciclos de condicionamento fisiológico com diferentes nutrientes e giberelina na qualidade fisiológica de sementes de Brachiaria brizantha cv. MG-5. O trabalho foi conduzido no Laboratório de Análise de Sementes da Universidade Estadual de Mato Grosso do Sul/Unidade Universitária de Cassilândia, de março a abril de 2013. O delineamento experimental foi o inteiramente casualizado, em esquema fatorial $3 \times 3$, constituído por primeiro ciclo de hidratação [controle (água), nitrato de potássio $\left(\mathrm{KNO}_{3}\right)$ e giberelina $\left(\mathrm{GA}_{3}\right)$ ], e segundo ciclo de hidratação [água, nitrato de cálcio $\left(\mathrm{Ca}\left(\mathrm{NO}_{3}\right)_{2}\right)$ e testemunha (sem condicionamento)], com quatro repetições. $\mathrm{O}$ primeiro e o segundo ciclo de hidratação foram via imersão direta por 2 horas à $25{ }^{\circ} \mathrm{C}$, seguido de secagens para as sementes atingirem o equilíbrio higroscópico. Foram realizados os testes de germinação, vigor, viabilidade das sementes e crescimento inicial de plântulas. $\mathrm{O}$ emprego de um ciclo de hidratação com nutriente e giberelina não influencia na geminação da semente, na emergência e no crescimento inicial das plântulas de $B$. brizantha, porém, se verificou que após um ciclo de hidratação, as sementes podem passar por mais um ciclo de hidratação quando se utilizada nitrato de cálcio na solução.

PALAVRAS-CHAVE: Cv. MG-5; imersão; germinação; vigor.

\section{PRIMING WITH NUTRIENTS AND GIBBERELLIC ACID ON THE QUALITY OF BRACHIARIA SEEDS}

\begin{abstract}
The priming agents to seeds can result in increased production and improve physiological quality of seeds. The objective was to evaluate the influence of priming cycles with different nutrients and gibberellin on the physiological quality of Brachiaria brizantha cv. MG-5 seeds. The study was conducted at the Seed Analysis Laboratory of the Mato Grosso do Sul State University, in Cassilândia-MS, from March to April 2013. The experimental design was completely randomized in a $3 \times 3$ factorial, composed of first hydration cycle [control (water), potassium nitrate $\left(\mathrm{KNO}_{3}\right)$ and gibberellic acid $\left(\mathrm{GA}_{3}\right)$ ], and second hydration cycle [water, calcium nitrate $\left(\mathrm{Ca}\left(\mathrm{NO}_{3}\right)_{2}\right)$ and control (unconditioned)], with four replications. The first and second hydration cycle of seeds was carried out by direct immersion for 2 hours at $25{ }^{\circ} \mathrm{C}$, followed by drying of the seeds to reach equilibrium moisture content. Germination, vigor, seed viability and early seedling growth were measured. The use of a hydration cycle with nutrient or gibberellic acid did not affect seed germination, the emergence and early growth of Brachiaria seedlings; however, after a hydration cycle, the seeds can be subjected to another hydration cycle when using calcium nitrate solution.
\end{abstract}

KEY WORDS: Cv. MG-5; soaking; germination; vigor. 


\section{INTRODUÇÃO}

Dentre as diversas espécies de gramíneas forrageiras, a Brachiaria brizantha tem sido considerada como umas das principais utilizadas nas pastagens tropicais cultivadas no país.

Tratamentos pré-germinativos podem propiciar melhor desempenho das sementes e o condicionamento fisiológico, segundo Marcos Filho (2005), permite à hidratação controlada em sementes, promovendo reparo das membranas celulares e componentes da estrutura celular, incentivando o metabolismo da semente durante as fases I (embebição) e II (mobilização de reservas), mas impedindo a protusão da radícula (fase III).

Aragão et al. (2003) ao estudarem a pré - embebição com o emprego de ácido giberélico em sementes de milho super doce (Zea mays) verificaram um incremento na germinação e vigor das sementes mediante este tratamento.

Bonome et al. (2006) verificaram que sementes de Brachiaria brizantha cv. Marandu osmocondicionadas em solução de $\mathrm{KNO}_{3}$ pelo período de 12 horas apresentam uniformidade de germinação superior a testemunha (PEG 6000). Oliveira e Gomes-Filho (2010) ao trabalhar com sementes de sorgo verificaram que o envelhecimento artificial ( 72 horas) vem a prejudicar a qualidade de sementes desta espécie, todavia estes efeitos podem ser parcialmente revertidos pela técnica do condicionamento.

O objetivo foi avaliar a influencia de ciclos hidratação através do condicionamento fisiológico com nutrientes e giberelina na qualidade fisiológica de sementes de $B$. brizantha cv. MG-5.

\section{MATERIAL E MÉTODOS}

O experimento foi desenvolvido no Laboratório de Análise de Sementes da Universidade Estadual de Mato Grosso do Sul - Unidade Universitária de Cassilândia (UEMS/UUC), entre os meses de Março a Abril de 2013.

Foram utilizadas sementes de Brachiaria brizantha cv. MG-5, sem tratamento prévio, cuja qualidade fisiológica e viabilidade foram avaliadas antes das instalações do experimento (Tabela 1).

Tabela 1. Grau de umidade, massa de 1000 sementes, tetrazólio, condutividade elétrica, germinação e emergência de sementes de B. brizantha cv. MG-5. Cassilândia, MS. 2013.

\begin{tabular}{cccccc}
\hline $\begin{array}{c}\text { Grau de } \\
\text { umidade } \\
\text { das }\end{array}$ & $\begin{array}{c}\text { Massa de } \\
1000 \\
\text { sementes }\end{array}$ & Tetrazólio & $\begin{array}{c}\text { Condutividade } \\
\text { elétrica }\end{array}$ & Germinação & Emergência \\
\hline$----\%----$ & ----- g----- & $----\%$---- & $--\mu \mathrm{Sm}^{-1} \mathrm{~g}^{-1}--$ & $------------\%$---------- \\
\hline 11,32 & 10,96 & 80 & 39,31 & 48 & 40 \\
\hline
\end{tabular}

Anterior a aplicação dos tratamentos, as sementes de Brachiaria brizantha cv. MG-5 foram submetidas à escarificação química com ácido sulfúrico concentrado $\left(\mathrm{H}_{2} \mathrm{SO}_{4}\right)$ por 5 minutos. Posteriormente, as sementes foram lavadas em água corrente deionizada e colocadas para secar até para atingirem a umidade de equilíbrio higroscópico.

Foi realizado o condicionamento fisiológico por hidratação das sementes sob imersão direta em diferentes soluções, perfazendo um delineamento experimental inteiramente casualizado, em esquema fatorial $3 \times 3$, constituído por: primeiro ciclo de hidratação das 
sementes (controle - condicionamento em água, nitrato de potássio - $\mathrm{KNO}_{3} \quad 0,2 \%$ e Giberelina - $50 \mathrm{mg} \mathrm{L}^{-1}$ de $\mathrm{GA}_{3}$ ) e segundo ciclo de hidratação que ocorreu após secagem das sementes que passaram pelo primeiro ciclo de condicionamento [testemunha - sem condicionamento, água e nitrato de cálcio - $\left.\mathrm{Ca}\left(\mathrm{NO}_{3}\right)_{2} 0,2 \%\right]$, com quatro repetições, sendo utilizados $6 \mathrm{~g}$ de sementes para cada tratamento, com quatro repetições.

Para o condicionamento fisiológico das sementes, as mesmas foram colocadas em imersão direta nas diferentes soluções (100 mL de solução, em copos plásticos) utilizadas e mantidas em um germinador a $25^{\circ} \mathrm{C}$, por 2 horas. Posteriormente as sementes foram postas para secar sob papel toalha, para atingirem a umidade de equilíbrio higroscópico.

As sementes de cada tratamento foram avaliadas por meio dos seguintes parâmetros ou testes:

Primeira contagem de germinação - Foi realizada juntamente com o teste de germinação, registrando-se a porcentagem de plântulas normais aos 7 dia após a instalação do ensaio, de acordo com os critérios estabelecidos pelas Regras de Análise de Sementes (BRASIL, 2009). Os resultados foram expressos em porcentagem de plântulas normais.

Teste de germinação - Foi realizado com 4 sub-amostras de 50 sementes em gerbox mantendo-se a temperatura de $25^{\circ} \mathrm{C}$, com fotoperíodo de 12 horas. As contagens de plântulas normais foram realizadas aos 7 e 21 dias após a semeadura, de acordo com os critérios estabelecidos pelas Regras de Análise de Sementes (BRASIL, 2009). Os resultados foram expressos em porcentagem de plântulas normais.

Índice de velocidade de germinação (IVG) - Foi calculado pelo somatório do número de sementes germinadas a cada dia, dividido pelo número de dias decorridos entre a semeadura e a germinação, de acordo com a fórmula definida por Maguire (1962), apresentada a seguir:

$\mathrm{IVG}=\mathrm{N} 1 / \mathrm{D} 1+\mathrm{N} 2 / \mathrm{D} 2+\ldots .+\mathrm{Nn} / \mathrm{Dn}$ onde;

IVG = índice de velocidade de germinação;

$\mathrm{N} 1, \mathrm{~N} 2, \ldots ., \mathrm{Nn}=$ número de plântulas germinadas a $1,2, \ldots . ., \mathrm{n}$ dias após a semeadura, respectivamente;

D1, D2,...., Dn = número de dias após a implantação do teste.

Teste de viabilidade das sementes remanescentes do teste de germinação - As sementes foram submetidas à um corte manual em sentido longitudinal, através da metade do eixo embrionário, em até aproximadamente três quartos do comprimento do endosperma, com o auxílio de um bisturi e imersas (as duas partes unidas) em solução de 2,3,5 trifenil cloreto de tetrazólio $0,1 \%$, por aproximadamente 4 horas. Posteriormente, as sementes foram lavadas em água corrente, abertas para facilitar a visualização e foi realizada a avaliação dos embriões de ambas as partes para a identificação e contagem das sementes viáveis e mortas remanescentes do teste de germinação, em porcentagem.

Teste de condutividade elétrica - Para avaliação da condutividade elétrica da solução de embebição de sementes, foi utilizado o teste de "condutividade de massa" ou sistema de copo. Realizada por meio de quatro sub-amostras de 50 sementes, sendo que cada subamostra (repetições) foi pesada com precisão de pelo menos duas casas decimais, a seguir colocada para embeber em um recipiente contendo $75 \mathrm{~mL}$ de água deionizada e, então, mantida em uma câmara (germinador) à temperatura de $25^{\circ} \mathrm{C}$ durante 24 horas. Após o período de 24 horas foi realizado a leitura da condutividade elétrica na solução de embebição 
em condutivímetro. Os resultados foram expressos em $\mu \mathrm{S} \mathrm{cm} \mathrm{cm}^{-1}$ de sementes (VIEIRA; KRYZANOWSKE, 1999).

Primeira contagem de emergência - Foi conduzido em casa de vegetação juntamente com o teste de emergência, registrando-se a porcentagem de plântulas emergidas aos 7 dias após a instalação do ensaio, considerando-se como plântulas emergidas com comprimento da parte aérea não inferior a $20 \mathrm{~mm}$. Os resultados foram expressos em porcentagem de plântulas emergidas.

Teste de emergência - Foi conduzido em casa de vegetação utilizando quatro subamostras de 50 sementes por tratamento, com semeadura realizada à $1 \mathrm{~cm}$ de profundidade em bandejas previamente perfuradas na parte de baixo para facilitar a drenagem de água, utilizando-se vermiculita como substrato. Registrou-se a porcentagem de plântulas emergidas até estabilização da emergência das mesmas, com limite de 28 dias após a semeadura, considerando-se como plântulas emergidas as com comprimento da parte aérea não inferior a $20 \mathrm{~mm}$. Os resultados foram expressos em porcentagem de plântulas emergidas.

Índice de velocidade de emergência (IVE) - Foi conduzido em casa de vegetação juntamente com o teste de emergência de plântulas. As avaliações foram realizadas mediante a contagem diária do número de plântulas emergidas até estabilização com limite de 28 dias após a semeadura e o cálculo do índice de velocidade foi efetuado, conforme Maguire (1962), apresentada a seguir:

$\mathrm{IVE}=\mathrm{N} 1 / \mathrm{D} 1+\mathrm{N} 2 / \mathrm{D} 2+\ldots .+\mathrm{Nn} / \mathrm{Dn}$ onde;

IVE = índice de velocidade de emergência;

$\mathrm{N} 1, \mathrm{~N} 2, \ldots . ., \mathrm{Nn}$ = número de plântulas germinadas a 1, 2,...., n dias após a semeadura, respectivamente;

D1, D2,...., Dn = número de dias após a implantação do teste.

Os dados, foram avaliados por meio da análise de variância pelo teste F. Quando significativo ao nível de $5 \%$ de probabilidade, aplicou-se o teste de Tukey. Foi utilizado o programa SANEST (ZONTA; MACHADO, 1986). Para a variável sementes remanescentes inviáveis foi realizada a transformação através do arco seno de raiz $(\mathrm{x} / 100)$.

\section{RESULTADOS E DISCUSSÃO}

O segundo ciclo de hidratação exerceu influencia sob a primeira contagem de germinação, germinação total, índice de velocidade de germinação (IVG) e sementes remanescentes inviáveis (Tabela 2).

O emprego do nitrato de cálcio no segundo ciclo de hidratação proporcionou desempenho superior para primeira contagem de germinação, germinação total e IVG em relação ao emprego da água, porem não de diferiu da testemunha. Maior número de sementes remanescentes inviáveis foi verificado empregando-se água no segundo ciclo de hidratação em relação ao emprego do nitrato de cálcio, não se diferindo da testemunha.

Evidenciou-se que sementes após um ciclo de hidratação, podem passar por mais um ciclo de hidratação quando se utilizada nitrato de cálcio (osmocondicionamento) na solução de hidratação das mesmas, pois o uso do hidrocondicionamento (água) propiciou menores valores de primeira contagem de germinação, germinação total, IVG e maior número de sementes mortas remanescente em relação ao osmocondicionamento (Tabela 2). 
O emprego de giberelina e nitrato de potássio no primeiro ciclo de hidratação não exerceram influencia sob os padrões relacionados à germinação de sementes de Brachiaria brizantha cv. MG-5 (Tabela 2).

Tabela 2. Primeira contagem da germinação e germinação total (7 e 21 dias), índice de velocidade de germinação (IVG) e sementes remanescentes inviáveis do teste de germinação em função de primeiro e segundo ciclo de hidratação em sementes de Brachiaria brizantha cv. MG-5. Cassilândia, MS. 2013.

\begin{tabular}{|c|c|c|c|c|c|}
\hline & \multirow[b]{2}{*}{ Tratamentos } & \multicolumn{2}{|c|}{ Germinação (\%) } & \multirow[b]{2}{*}{ IVG } & \multirow{2}{*}{$\begin{array}{c}\text { Sementes } \\
\text { remanescentes } \\
\text { inviáveis }(\%)\end{array}$} \\
\hline & & $\begin{array}{l}\text { Primeira } \\
\text { contagem }\end{array}$ & Total & & \\
\hline \multirow{3}{*}{$\begin{array}{l}\text { Primeiro } \\
\text { Ciclo de } \\
\text { Hidratação } \\
\text { (PC) }\end{array}$} & Controle - água & 82 & 83 & 5,86 & 16 \\
\hline & Giberelina & 83 & 83 & 5,91 & 15 \\
\hline & $\mathrm{KNO}_{3}$ & 84 & 85 & 6,02 & 14 \\
\hline \multirow{3}{*}{$\begin{array}{c}\text { Segundo } \\
\text { Ciclo de } \\
\text { Hidratação } \\
\text { (SC) }\end{array}$} & Testemunha & ${ }^{\mathrm{M}} 82 \mathrm{ab}$ & $84 \mathrm{ab}$ & $5,92 \mathrm{ab}$ & $15 \mathrm{ab}$ \\
\hline & Água & $79 \mathrm{~b}$ & $80 \mathrm{~b}$ & $5,66 \mathrm{~b}$ & $18 \mathrm{a}$ \\
\hline & $\mathrm{Ca}\left(\mathrm{NO}_{3}\right)_{2}$ & $87 \mathrm{a}$ & $87 \mathrm{a}$ & $6,2 \mathrm{a}$ & $12 \mathrm{~b}$ \\
\hline \multirow{3}{*}{$\mathrm{F}$} & $\mathrm{PC}$ & $0,42^{\text {N.S. }}$ & $0,44^{\text {N.S. }}$ & $0,42^{\text {N.S. }}$ & $0,31^{\text {N.S. }}$ \\
\hline & $\mathrm{SC}$ & $4,67^{*}$ & $4,25^{*}$ & $4,79^{*}$ & $3,27^{*}$ \\
\hline & PC X SC & $0,79^{\text {N.S. }}$ & $0,49^{\text {N.S. }}$ & $0,60^{\text {N.S. }}$ & $0,48^{\text {N.S. }}$ \\
\hline \multicolumn{2}{|c|}{ C. V. $(\%)$} & 7,14 & 7,55 & 7,30 & 20,81 \\
\hline
\end{tabular}

${ }^{\mathrm{M}}$ Médias seguidas de letras diferentes na coluna diferem-se estatisticamente entre si pelo teste de Tukey a 5\% de probabilidade;

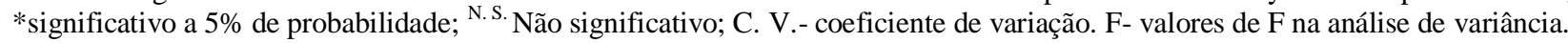

Os resultados obtidos neste trabalho divergem do obtido por Câmara e StacciariniSeraphin (2002) que verificaram ao trabalhar com sementes de B. brizantha cv. Marandu que ocorreu aumento na taxa de germinação quando submetida a tratamento com giberelina $(0,1$ mmol. $\mathrm{m}^{-3}$ ). Já Dantas et al. (2001) verificaram que a aplicação de ácido giberélico na concentração em torno de 0,250 mmol. $1^{-1}$ aumentou a germinação de sementes de Brachiaria plantaginea. Aragão et al. (2001) verificaram que sementes de milho super doce condicionadas com ácido giberélico (50 ou $100 \mathrm{mg} .1^{-1}$ ) apresentaram eficiência na promoção da germinação e primeira contagem de germinação.

Interação significativa entre o primeiro e segundo ciclo de hidratação foi verificada para condutividade elétrica (Tabela 3). Sementes condicionadas com água (controle) e nitrato de potássio, no primeiro ciclo, ao passarem por um segundo ciclo de hidratação com água e nitrato de cálcio obtiveram menor valor de leitura no teste de condutividade elétrica. Possivelmente o condicionamento com água e nitrato de cálcio de segundo ciclo influenciaram na reorganização do sistema de membranas das sementes, ocasionando menores conteúdos de lixiviados dentro da água de embebição.

Os dados obtidos para condutividade elétrica corroboram com os de Cardoso et al. (2014) que estudaram o condicionamento fisiológico com o emprego de $\mathrm{KNO}_{3}$ em sementes de Brachiria brizantha e verificaram que este método é capaz de propicia reparo no sistema de membranas.

Alem da eficiência do nitrato de potássio, pode se verificar que sua interação com água e nitrato de cálcio em outro ciclo de hidratação potencializa e melhora os resultados da condutividade (Tabela 3), por conseguinte, o vigor das sementes. 
Tabela 3. Desdobramento da interação significativa para condutividade elétrica em função de primeiro e segundo ciclo de hidratação em sementes de Brachiaria brizantha cv. MG-5. Cassilândia, MS. 2013.

\begin{tabular}{lccc}
\hline \multicolumn{4}{c}{ Condutividade elétrica $\left(\mu \mathrm{S} \mathrm{cm}^{-1} \mathrm{~g}^{-1}\right)$} \\
\hline \multirow{2}{*}{ Primeiro Ciclo de Hidratação } & \multicolumn{3}{c}{ Segundo Ciclo de Hidratação } \\
\cline { 2 - 4 } Controle - água & Testemunha & Água & $\mathrm{Ca}\left(\mathrm{NO}_{3}\right)_{2}$ \\
Giberelina & $\mathrm{M}_{45,95 \mathrm{aA}}$ & $18,14 \mathrm{aB}$ & $21,89 \mathrm{aB}$ \\
$\mathrm{KNO}_{3}$ & $19,94 \mathrm{bA}$ & $17,98 \mathrm{aA}$ & $19,34 \mathrm{aA}$ \\
\hline $\mathrm{C} . \mathrm{V} .(\%)$ & $21,98 \mathrm{bA}$ & $13,88 \mathrm{aB}$ & $12,71 \mathrm{bB}$ \\
\hline${ }^{\mathrm{M}}$ Médias seguidas de letras diferentes minúsculas nas colunas e maiúsculas na linha, dentro dos fatores condicionamentos, \\
diferem estatisticamente entre si pelo teste de Tukey a 5\% de probabilidade; C.V. coeficiente de variação.
\end{tabular}

A primeira contagem de emergência, emergência, índice de velocidade de emergência, altura de plantas e comprimento de raiz não foram influenciadas pelos fatores empregados (Tabela 4).

Tabela 4. Primeira contagem da emergência e emergência (7 e 21 dias), IVE (índice de velocidade de emergência), altura da parte aérea (AP) e comprimento de raiz (CR) em função de primeiro e segundo ciclo de hidratação em sementes de Brachiaria brizantha cv. MG-5. Cassilândia, MS. 2013.

\begin{tabular}{|c|c|c|c|c|c|c|}
\hline & \multirow[b]{2}{*}{ Tratamentos } & \multicolumn{2}{|c|}{ Emergência (\%) } & \multirow[b]{2}{*}{ IVE } & \multicolumn{2}{|c|}{ Crescimento $(\mathrm{cm})$} \\
\hline & & $\begin{array}{l}\text { Primeira } \\
\text { contagem }\end{array}$ & Total & & $\mathrm{AP}$ & $\mathrm{CR}$ \\
\hline \multirow{3}{*}{$\begin{array}{c}\text { Primeiro } \\
\text { Ciclo de } \\
\text { Hidratação } \\
(\mathrm{PC})\end{array}$} & Controle - água & 82 & 84 & 5,86 & 13,79 & 15,74 \\
\hline & Giberelina & 79 & 81 & 5,71 & 13,85 & 15,15 \\
\hline & $\mathrm{KNO}_{3}$ & 80 & 82 & 5,77 & 14,09 & 15,01 \\
\hline \multirow{3}{*}{$\begin{array}{c}\text { Segundo } \\
\text { Ciclo de } \\
\text { Hidratação } \\
\text { (SC) }\end{array}$} & Testemunha & 79 & 83 & 5,78 & 14,02 & 14,65 \\
\hline & Água & 82 & 84 & 5,84 & 13,86 & 15,32 \\
\hline & $\mathrm{Ca}\left(\mathrm{NO}_{3}\right)_{2}$ & 79 & 81 & 5,72 & 13,87 & 15,93 \\
\hline \multirow{3}{*}{$\mathrm{F}$} & $\mathrm{PC}$ & $0,86^{\mathrm{N} . S .}$ & $0,75^{\mathrm{N} . S .}$ & $0,37^{\text {N.S. }}$ & $0,73^{\text {N.S. }}$ & $0,59^{\text {N.S. }}$ \\
\hline & $\mathrm{SC}$ & $0,79^{\text {N.S. }}$ & $0,45^{\mathrm{N} . S}$ & $0,27^{\text {N.S. }}$ & $0,22^{\text {N.S. }}$ & $1,62^{\text {N.S. }}$ \\
\hline & $\mathrm{PC} \times \mathrm{SC}$ & $0,41^{\text {N.S. }}$ & $0,66^{\text {N.S. }}$ & $0,36^{\text {N.S. }}$ & $1,85^{\text {N.S. }}$ & $1,41^{\text {N.S. }}$ \\
\hline \multicolumn{2}{|c|}{ C.V. (\%) } & 6,80 & 7,32 & 7,11 & 4,71 & 11,42 \\
\hline
\end{tabular}

Os dados obtidos à partir do teste de emergência divergem dos de Aragão et al. (2001) que ao trabalharem com regulador de crescimento no condicionamento de sementes de milho super doce (Zea mays) verificaram incremento na emergência e índice de velocidade de emergência.

\section{CONCLUSÕES}

1. O emprego de um ciclo de hidratação com nutrientes e giberelina não influenciam, dentro das condições testadas, na geminação, emergência e crescimento inicial de plantas de B. brizantha,

2. Após um ciclo de hidratação as sementes podem passar por mais um ciclo de hidratação ao se empregar nitrato de cálcio. 
3. O emprego de nitrato de potássio em primeiro ciclo de hidratação associado a um segundo ciclo com água e nitrato de cálcio propicia reparo no sistema de membranas das sementes de $B$. brizantha.

\section{REFERÊNCIAS BIBLIOGRÁFICAS}

ARAGÃO, C. A.; LIMA, M. W. P.; MORAIS.; ONO, E. O.; BOARO, C. S. F.; RODRIGUES, J. D.; NAKAGAWA, J.; CAVARIANI, C. Fitorreguladores na germinação e no vigor de plântulas de milho super doce. Revista Brasileira de Sementes, Brasília-DF, v.23, n.1, p. 62-67, 2001.

ARAGÃO, C. A.; DANTAS, B. F.; ALVES, E. ; CATANEO, A. C. ; CAVARIANI, C.; NAKAGAWA, J. Atividade amilolítica e qualidade fisiológica de sementes armazenadas de milho super doce tratadas com ácido giberélico. Revista Brasileira de Sementes, Pelotas-RS, v. 25 , n. 1, p. 43-48, 2003.

BRASIL. Ministério da Agricultura, Pecuária e Abastecimento. Regras para Análise de Sementes. SDA/CGAL. Brasília-DF: MAPA/ACS, 2009.

BONOME, L. T. S.; GUIMARÃES, R. M.; OLIVEIRA, J. A.; ANDRADE, V. C.; CABRAL, P. S. Efeito do condicionamento osmótico em sementes de Brachiaria brizantha cv. Marandu. Ciência e Agrotecnologia, Lavras-MG, v. 30, n. 3, p. 422-428, 2006.

CÂMARA, H. H. L. L.; STACCIARINI-SERAPHIN, E. Germinação de sementes de Brachiaria brizantha cv. Marandu sob diferentes períodos de armazenamento e tratamento hormonal. Pesquisa Agropecuária Tropical, Goiânia-GO, v. 32, n. 1, p. 21-28, 2002.

CARDOSO, E. D.; SÁ, M. E.; HAGA, K. I.; BINOTTI, F. F. S.; NOGUEIRA, D. N. ; VALÉRIO FILHO, W. V. Desempenho fisiológico e superação de dormência em sementes de Brachiaria brizantha submetidas a tratamento químico e envelhecimento artificial. Semina: Ciências Agrárias, Londrina-PR, v. 35, n. 1, p. 21-38, 2014.

DANTAS, B. F.; ALVES, E.; ARAGÃO, C. A.; TOFANELLI, M. B. D.; CORRÊA, M. R.; CAVARIANI, C.; NAKAGAWA, J. Germinação de sementes de capim marmelada (Brachiaria plantaginea (Link.)) tratadas com acido giberélico. Revista Brasileira de Sementes, Brasília-DF, v. 23, n. 2, p. 27-34, 2001.

MAGUIRE, J. D. Speed of germination-aid in selection and evaluation for seedling emergence and vigor. Crop Science, Madison, v. 2, n. 1, p. 176-177, 1962.

MARCOS FILHO, J. Fisiologia de sementes de plantas cultivadas. Piracicaba-SP: FEALQ, 2005. $495 \mathrm{p}$.

OLIVEIRA, A. B.; GOMES-FILHO, E. Efeito do condicionamento osmótico na germinação e vigor de sementes de sorgo com diferentes qualidades fisiológicas. Revista Brasileira de Sementes, Brasília-DF, v. 32, n. 3, p. 25-34, 2010.

VIERA, R. D.; KRYZANOWSKI, F. C. Teste de condutividade elétrica. In: KRYZANOWSKI, F.C.; VIEIRA, R. D.; FRANÇA NETO, J. B. (Ed.). Vigor de sementes: conceitos e testes. Londrina-PR: ABRATES, 1999. cap.4. p. 4.1-4.26

ZONTA, E. P.; MACHADO, A. A. Sistema de Análise Estatística para microcomputadores - SANEST. Pelotas-RS: UFPel, Instituto de Física e matemática, 1986. $150 \mathrm{p}$. 